\title{
Multifrequency radar observations of clouds and precipitation including the G-band
}

\author{
Katia Lamer ${ }^{1}$, Mariko Oue ${ }^{2}$, Alessandro Battaglia ${ }^{3,4,5}$, Richard J. Roy ${ }^{6}$, Ken B. Cooper ${ }^{6}$, Ranvir Dhillon ${ }^{5}$, and \\ Pavlos Kollias ${ }^{1,2}$ \\ ${ }^{1}$ Department of Environmental and Climate Sciences, Brookhaven National Laboratory, Upton, NY, USA \\ ${ }^{2}$ Division of Atmospheric Sciences, Stony Brook University, Stony Brook, NY, USA \\ ${ }^{3}$ National Centre for Earth Observation, Leicester, UK \\ ${ }^{4}$ DIATI Department of Environment, Land and Infrastructure Engineering, Politecnico di Torino, Turin, Italy \\ ${ }^{5}$ Department of Physics and Astronomy, University of Leicester, Leicester, UK \\ ${ }^{6}$ Jet Propulsion Laboratory, California Institute of Technology, Pasadena, CA, USA
}

Correspondence: Katia Lamer (klamer@bnl.gov)

Received: 14 December 2020 - Discussion started: 17 December 2020

Revised: 24 March 2021 - Accepted: 1 April 2021 - Published: 20 May 2021

\begin{abstract}
Observations collected during the 25 February 2020 deployment of the Vapor In-Cloud Profiling Radar at the Stony Brook Radar Observatory clearly demonstrate the potential of G-band radars for cloud and precipitation research, something that until now was only discussed in theory. The field experiment, which coordinated an X-, Ka-, $\mathrm{W}$ - and G-band radar, revealed that the $\mathrm{Ka}-\mathrm{G}$ pairing can generate differential reflectivity signal several decibels larger than the traditional $\mathrm{Ka}-\mathrm{W}$ pairing underpinning an increased sensitivity to smaller amounts of liquid and ice water mass and sizes. The observations also showed that G-band signals experience non-Rayleigh scattering in regions where Ka- and W-band signal do not, thus demonstrating the potential of G-band radars for sizing sub-millimeter ice crystals and droplets. Observed peculiar radar reflectivity patterns also suggest that G-band radars could be used to gain insight into the melting behavior of small ice crystals.

G-band signal interpretation is challenging, because attenuation and non-Rayleigh effects are typically intertwined. An ideal liquid-free period allowed us to use triple-frequency $\mathrm{Ka}-\mathrm{W}-\mathrm{G}$ observations to test existing ice scattering libraries, and the results raise questions on their comprehensiveness.

Overall, this work reinforces the importance of deploying radars (1) with sensitivity sufficient enough to detect small Rayleigh scatters at cloud top in order to derive estimates of path-integrated hydrometeor attenuation, a key constraint for microphysical retrievals; (2) with sensitivity sufficient
\end{abstract}

enough to overcome liquid attenuation, to reveal the larger differential signals generated from using the G-band as part of a multifrequency deployment; and (3) capable of monitoring atmospheric gases to reduce related uncertainty.

\section{Introduction}

Over the past 20 years, millimeter-wavelength radars have become the instrument of choice for the study of cloud and precipitation. Today, radars operating at 35 and $94 \mathrm{GHz}$ frequencies are routinely operated at ground-based observatories (e.g., U.S. Department of Energy Atmospheric Radiation Measurement, ARM, user facilities; Stokes and Schwartz, 1994; and the Aerosol, Clouds and Trace Gases Research Infrastructure, ACTRIS; Pappalardo, 2018) and from a variety of ship-based and airborne platforms (Kollias et al., 2007b). In space, the CloudSat $94 \mathrm{GHz}$ cloud profiling radar (CPR) has been operating since May 2006 (Stephens et al., 2002) and the Earth Cloud Aerosol and Radiation Explorer (EarthCARE), the first spaceborne Dopplerized cloud profiling radar, is expected to be launched in 2023 (Illingworth et al., 2015). Reasons for the popular use of millimeterwavelength radars include the facts that this frequency range is much more sensitive (in contrast to centimeter-wavelength radars) to cloud droplets and small ice crystals and that it allows for the collection of observations at excellent spa- 
tial resolution ( $\sim 30 \mathrm{~m}$; Kollias et al., 2020a). Although nonRayleigh scattering signatures in the radar Doppler spectrum can be exploited for sizing large raindrops and snow (i.e., Mie notches techniques; Kollias et al., 2002), it remains challenging to extract quantitative information about the size and mass of small hydrometeors using observations from standalone single-frequency millimeter-wavelength radars. For the most part, challenges arise since signal at any one frequency experiences both attenuation (related to particle mass) and scattering (related to particle habit and size), making it nearly impossible to disentangle these effects.

Fortunately, attenuation and scattering of radar signals are frequency dependent such that they can be exploited to retrieve independent information about particle mass, habit, or size, depending on the character of scattering. For instance, the observations from two (or more) radar frequencies within the same scattering regime, but different absorption regime, can be combined to isolate differential attenuation signals useful for the retrieval of liquid water content (Hogan et al., 2005; Zhu et al., 2019). Alternatively, observations collected at two (or more) radar frequencies experiencing similar signal absorption, but differential scattering, can be combined to reveal information about ice crystal habit and size (Kneifel et al., 2015). That being said, modern multifrequency pairings are limited because (i) they rely on frequencies that experience little differential attenuation in liquid clouds causing larger liquid water content retrieval uncertainty and (ii) they do not produce differential scattering signals for hydrometeors smaller than $800 \mu \mathrm{m}$, thus leaving a noticeable gap in our understanding of the microphysical properties of drizzle and small ice particles.

In response to these limitations, the research community has expressed an interest in developing radars operating at higher frequencies in the so-called G-band $(110-300 \mathrm{GHz}$; Battaglia et al., 2014). Compared to a Ka-W (35-94 GHz) frequency pair, a $\mathrm{Ka}-\mathrm{G}$ frequency pair should experience measurable differential attenuation at smaller water mass amounts and non-Rayleigh scattering at smaller particle sizes (e.g., Battaglia et al., 2014; Hogan and Illingworth, 1999; Lhermitte, 1988). What is more, a Ka-G frequency pair is expected to always produce differential signals larger than that of traditional pairs, thus increasing the resilience to noise and precision of hydrometeor mass or size retrievals. Other applications of G-band and sub-millimeter-wavelength radars come from the presence of a water vapor absorption line at $183 \mathrm{GHz}$. By tuning the radar frequency between positions of higher and lower absorption near a water vapor line, (e.g., 183 or $325 \mathrm{GHz}$ ), G-band radars can be used to profile water vapor using the differential absorption radar (DAR) technique (Battaglia and Kollias, 2019; Lebsock et al., 2015; Roy et al., 2018; Cooper et al., 2018).

Surprisingly, the first G-band radar for meteorological applications was only built in the late 1980s; McIntosh et al. (1988) designed a $215 \mathrm{GHz}$ non-Dopplerized highpower extended interaction klystron transmitter radar system and demonstrated that it was capable of making backscatter measurements from terrain targets at ranges of several kilometers under normal atmospheric conditions. Mead et al. (1989) attempted to use the system to characterize clouds and fog and realized that it did not possess sufficient sensitivity to detect clouds and light precipitation. Thirty years past before we saw the development of the next generation of G-band radars. In 2018, thanks to significant technological advancements in radar front ends, mixers and low-power wide-bandwidth solid-state G-band sources, the Jet Propulsion Laboratory (JPL) developed a highly sensitive non-Dopplerized frequency-modulated continuous-wave (FMCW) G-band radar tunable from 167 to $174.8 \mathrm{GHz}$ (i.e., DAR; Cooper et al., 2020; Roy et al., 2018). The system, named Vapor In-Cloud Profiling Radar (VIPR), was deployed during $7 \mathrm{~d}$ in April 2019 at the ARM Southern Great Plains facility. This first deployment aimed to evaluate VIPR's ability to exploit differential absorption signatures to retrieved in-cloud humidity profiles (Roy et al., 2020). VIPR's retrievals were evaluated against coincident measurements from ARM water vapor sensors, with the primary comparison coming from frequently launched radiosondes. Furthermore, VIPR's integrated water vapor measurement capabilities in clear air columns were investigated by comparing with both radiosonde and Raman lidar profiles. These comparisons highlighted VIPR's ability to profile in-cloud water vapor with high resolution $(<200 \mathrm{~m})$ and accuracy (RMSE $<1 \mathrm{~g} \mathrm{~m}^{-3}$ ), especially within the planetary boundary layer. This deployment also helped identify regimes where VIPR's specific DAR channel locations (i.e., 167 and $174.8 \mathrm{GHz}$ ) resulted in retrieval biases stemming from frequency-dependent hydrometeor scattering properties. Shortly thereafter, VIPR was deployed aboard a DHC6-300 aircraft from Twin Otter International Ltd. for its first airborne measurement campaign in November 2019 and January 2020 (Roy et al., 2021).

VIPR was deployed again in February 2020 at the Stony Brook Radar Observatory (SBRO) to demonstrate the capability of G-band radars for characterizing rain, ice crystals and snow. There, it collected observations alongside three radars operating respectively at $9.4,35$ and $94 \mathrm{GHz}$, thus providing first light multifrequency radar observations including the G-band. Here, we present the results of the quadruplefrequency radar field experiment that sampled a frontal system accompanied by prefrontal cirrus clouds followed by ice transitioning into light warm rain. The presented work demonstrates the value of using a G-band radar as part of a multifrequency radar observatory and underlines some important lessons learned and requirements needed for taking full advantage of G-band radar observations for cloud and precipitation microphysical studies. 


\section{Sensors and deployment information}

The SBRO is a fenced-in facility located on the edge of Stony Brook University's commuter parking lot located on Long Island, New York state, USA $\left(40^{\circ} 53^{\prime} 50^{\prime \prime} \mathrm{N}, 73^{\circ} 07^{\prime} 38^{\prime \prime} \mathrm{W}\right)$. The SBRO is equipped with a W-band profiling radar and a Ka-band scanning polarimetric radar, and (through a partnership with Raytheon) it also hosts two X-band dualpolarization low-power phased-array radars (Kollias et al., 2018). In addition to these radar systems, the SBRO is also equipped with a backscatter lidar, a long-range scanning Doppler lidar as well as a surface flux system, and three Parsivel $^{2}$ disdrometers. The observatory's equipment suite is completed by a sounding system and a small drone with integrated meteorological sensors. When combined, these systems have the ability to probe the atmosphere from surface to the top of the troposphere over horizontal scales of 20 $40 \mathrm{~km}$.

This section provides details specific to the operation of these systems during the deployment of the G-band VIPR radar on 25 February 2020, beginning with pictures of the instrument layout during the field deployment (Fig. 1). Like the pictures illustrate, all systems were installed in very close proximity in order to facilitate multifrequency retrievals.

\subsection{Vapor In-Cloud Profiling Radar (VIPR)}

VIPR is a first-of-its-kind solid-state G-band differential absorption radar (DAR). Its technical specifications are described in detail in Cooper et al. (2020) and Roy et al. (2020).

When it was deployed at the SBRO, VIPR transmitted $300 \mathrm{~mW}$ of power at 167 and $174.8 \mathrm{GHz}$, and it was operated in frequency-modulated continuous-wave (FMCW) mode with a chirp bandwidth of $10 \mathrm{MHz}$ and corresponding range resolution of $15 \mathrm{~m}$. With a single-pulse coherent integration time of $1 \mathrm{~ms}$, VIPR realizes a noise-equivalent reflectivity of $-40 \mathrm{dBZ}$ at $1 \mathrm{~km}$ range. To reduce random noise from radar speckle, 2000 individual pulses are incoherently averaged to form a single reflectivity profile, resulting in a temporal resolution of about $5 \mathrm{~s}$. All observations reported here utilize the noise floor subtraction technique detailed in Roy et al. (2018), and any observations with signal-to-noise ratio below $0 \mathrm{~dB}$ have been removed from this analysis. For the multifrequency analysis in this work, we only focus on the measurements at $167 \mathrm{GHz}$ since it experiences less gas absorption than VIPR's higher-frequency channel.

Around noon on 24 February 2020 ( $1 \mathrm{~d}$ before the official field deployment) VIPR was installed near but outside a large shipping container. That day, VIPR was mostly operated off zenith for calibration purposes (details in Sect. 3.2). On the official deployment day of 25 February 2020, VIPR continued operating next to the large shipping container but this time in vertically pointing mode. Following the onset of rain that day, VIPR's transmitter had to be turned off on a number of occasions to wipe water droplets off of the radar antenna (gaps seen in Fig. 8c). In some instances, we noted that strong radar returns from close-range rain caused an increase in the system noise floor of up to $20 \mathrm{~dB}$ stemming from broadband phase noise in the transmitted signal (Cooper et al., 2020). At 20:41 UTC, following the onset of heavier surface rain, VIPR was moved inside the adjacent container and pointed $40^{\circ}$ off zenith. Note that off-zenith observations collected during the official deployment were not analyzed as part of the current study.

\subsection{W-band profiling radar (ROGER)}

ROGER, named after late radar pioneer Roger Lhermitte, is a refurbished version of the W-band $(94.8 \mathrm{GHz})$ radar previously integrated into the Center for Interdisciplinary Remotely-Piloted Aircraft Studies Twin Otter aircraft (Mead et al., 2003). ROGER is a single-polarization $0.3^{\circ}$ beamwidth coherent frequency-modulated continuous-wave (CFMCW) radar with Doppler capability. Its range resolution is configurable between $5-150 \mathrm{~m}$, and it can detect targets up to $18.8 \mathrm{~km}$. ROGER was refurbished by SBRO staff for groundbased vertically pointing operations in 2017. The effort involved building a new metal frame to hold the radar's two 24 in. parabolic dish antennas and all the CFMCW electronics as well as installing a server computer and power supplies.

During VIPR's deployment, ROGER was set to operate with a range gate spacing of $30 \mathrm{~m}$ and collected a full radar Doppler spectrum every $4 \mathrm{~s}$, achieving a sensitivity of roughly $-30 \mathrm{dBZ}$ at $1 \mathrm{~km}$.

\subsection{Ka-band Scanning Polarimetric Radar (KASPR)}

KASPR is a mechanically scanning $0.3^{\circ}$ beamwidth Ka-band fully polarimetric radar. Further details about KASPR can be found in Kollias et al. (2020b).

For most of the VIPR deployment, until 21:00 UTC to be exact, KASPR was operating vertically pointing with $15 \mathrm{~m}$ range resolution and $13.6 \mathrm{~km}$ maximum range. It only transmitted horizontally polarized waves and collected a full co-polar and cross-polar radar Doppler spectrum every $1 \mathrm{~s}$, achieving a sensitivity of roughly $-42 \mathrm{dBZ}$ at $1 \mathrm{~km}$. Towards the end of the deployment, between 19:0624:00 UTC, KASPR's vertically pointing observations were supplemented every $5 \mathrm{~min}$ by a $15^{\circ}$ elevation plan position indicator scan (PPI) and a hemispheric range-height indicator scan (HS-RHI; Kollias et al., 2014). Both scan types were designed to collect dual-polarization observations at $45 \mathrm{~m}$ range resolution for a $30 \mathrm{~km}$ range. Note that the scanning observations were not analyzed as part of the current study.

\subsection{X-band dual-polarization phased-array radar (SKYLER)}

SKYLER is a dual-polarization X-band low-power phasedarray radar with an antenna beamwidth of $1.98^{\circ}$ in azimuth 

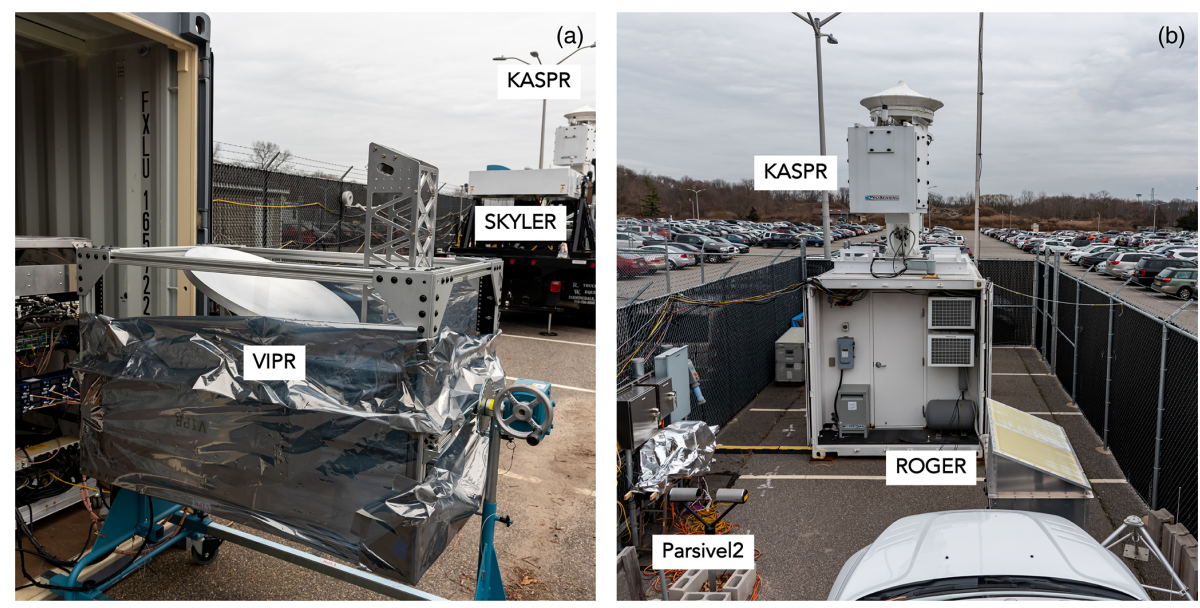

Figure 1. (a) Picture of the VIPR G-band radar system when it was deployed at the Stony Brook Radar Observatory. Also deployed at the observatory was a truck-mounted X-band phased-array radar named SKYLER (visible in panel a), the container-mounted parabolic-dish Ka-band radar named KASPR (visible in panels a and b), the FMCW W-band radar named ROGER (visible in panel b) and a Parsivel ${ }^{2}$ disdrometer (visible in panel b).

and $2.1^{\circ}$ in elevation at boresight. SKYLER's full range of capabilities are described in Kollias et al. (2020b).

During VIPR's deployment, SKYLER was only operated between 18:00-24:00 UTC. SKYLER was mounted on a rotation table installed on a mobile truck's flatbed oriented facing upward to enable the collection of vertically pointing observations. SKYLER was set to operate with a $2 \mu \mathrm{s}$ pulse and $48 \mathrm{~m}$ range gate spacing with maximum range of $9.85 \mathrm{~km}$. For collection of observations at $1 \mathrm{~s}$ time resolution, SKYLER was able to achieve a sensitivity of roughly $+15 \mathrm{dBZ}$ at $1 \mathrm{~km}$.

Because SKYLER's receiver blanking parameters were incorrectly set, its reflectivity observations collected below $1.25 \mathrm{~km}$ are biased low (hatching in Fig. 8a). Knowing that this bias could be corrected for, we elected to display these observations but only performed quantitative retrievals using SKYLER observations collected above $1.25 \mathrm{~km}$.

\subsection{Ancillary measurements}

One of the SBRO Parsivel ${ }^{2}$ laser optical disdrometers was operating during the VIPR's deployment. Vendor provided algorithms were used to classify the Parsivel ${ }^{2}$ drop observations into 32 separate size and velocity classes every $1 \mathrm{~min}$. In this work, Parsivel $^{2}$ observations are mainly used for conducting power calibration of all four radars.

The US National Weather Service (NWS) performs balloon-borne radiosonde measurements twice a day (00:00 and 12:00 UTC) from the Brookhaven National Laboratory campus in Upton, NY, $22 \mathrm{~km}$ east of the SBRO location. On 25 February 2020, SBRO staff and Stony Brook University students also launched two GRAW DFM-90 radiosondes at 01:46 and 15:44 UTC directly from the SBRO.
A Stream Line XR Doppler lidar and a Lufft CHM 15k backscatter lidar were also operated during the field experiment. The Doppler lidar was set to operate at $60 \mathrm{~m}$ range resolution and $1 \mathrm{~s}$ temporal resolution, providing estimates of air motion in the subcloud layer (not analyzed as part of the current study), while the backscatter lidar was set to operate with a $15 \mathrm{~m}$ range resolution and $15 \mathrm{~s}$ temporal resolution for monitoring the location of liquid layers.

\section{Radar data postprocessing}

Before they can be used to gain insight into atmospheric liquid and/or ice, high-frequency radar measurements must be post-processed to remove signal attenuation caused by atmospheric gases. Also, and especially in the context of multifrequency analysis, radar signals should be calibrated to improve the accuracy of quantitative retrievals. This section describes the steps used to postprocess and calibrate the radar observations collected by the VIPR, ROGER, KASPR and SKYLER radar and how these corrected observations are combined to conduct a multifrequency analysis.

\subsection{Gaseous attenuation correction}

When thermodynamic information is available, radio-wave propagation models can be used to estimate radar signal attenuation by atmospheric gases. Here we use the MPM93 model, an updated version of the millimeter-wave propagation model described by Liebe (1985) and Liebe et al. (1993) to compute two-way gas attenuation of X-, Ka-, Wand G-band signals for the conditions that occurred at 12:00 and 15:44 UTC on 25 February 2020 when two radiosondes were launched. Figure $2 a$ and $b$ show the profiles of temperature, dew-point temperature and humidity recorded at the 


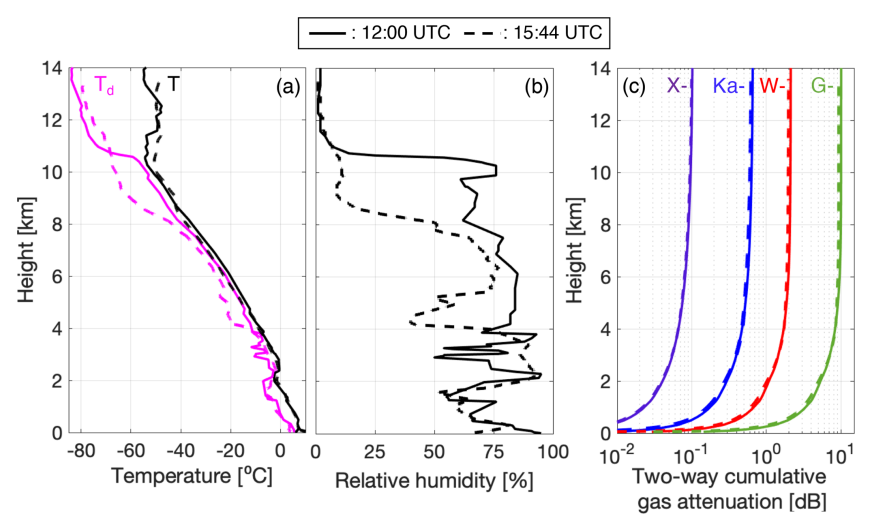

Figure 2. From sounding observations collected on 25 February 2020 at 12:00 UTC at the US NWS Upton site ( $22 \mathrm{~km}$ east of SBRO; solid lines) and at 15:44 UTC from the SBRO (dashed lines); profile of (a) temperature (black) and dew-point temperature (magenta), (b) relative humidity, (c) two-way water vapor attenuation at Xband (purple), Ka-band (blue), W-band (red) and G-band (green).

US NWS site $22 \mathrm{~km}$ east of SBRO at 12:00 UTC and at the SBRO at 15:44 UTC. The two-way gas attenuation profiles depicted in Fig. 2c confirm that millimeter radar signals, particularly at G-band, experience non-negligible gas attenuation. For this particular mid-latitudinal winter case, we estimate two-way gas attenuation at $11 \mathrm{~km}$ to reach $\sim 0.1 \mathrm{~dB}$ at $\mathrm{X}$-band, $\sim 0.5 \mathrm{~dB}$ at Ka-band, $\sim 2.0 \mathrm{~dB}$ at W-band and $\sim 10.0 \mathrm{~dB}$ at G-band. The large variability in gas attenuation from frequency to frequency, especially near water vapor absorption lines, is what allows DAR techniques to be used for water vapor profiling. On the upside the notable magnitude of the gas attenuation at higher frequencies (i.e., W-band but even more so G-band) makes them ideal frequencies to use for such application. On the downside, significant gas attenuation hinders the sensitivity of high-frequency radars to clouds and light precipitation.

Since the following analysis focuses on quantifying hydrometer properties, we correct all radar signals for two-way gas attenuation using the profiles derived above. The profiles estimated using the 12:00 UTC sounding are used to correct radar measurements collected before 13:52 UTC, while the ones estimated using the 15:44 UTC sounding are used to correct the rest of the radar measurements. The variability between the consecutive profiles can be used to get a sense of the uncertainty associated with using only two soundings to correct the daylong radar dataset.

\subsection{Radar reflectivity calibration}

On 24 February 2020 ( $1 \mathrm{~d}$ before the official field experiment), VIPR's calibration was verified using the methodology described in Roy et al. (2020); the exercise required hanging a small calibration sphere between two light posts roughly $200 \mathrm{~m}$ from the SBRO. KASPR's calibration is sim- ilarly checked twice a year by SBRO staff using a corner reflector located $300 \mathrm{~m}$ away from the SBRO.

SKYLER, ROGER and KASPR measurements are also sporadically calibrated using Parsivel ${ }^{2}$ measurement collected during rain episodes following a standard calibration technique similar to that described in Chandrasekar et al. (2015) and Kollias et al. (2019). In short, the Parsivel ${ }^{2}$ disdrometer particle size distribution (PSD) measurements are used as input to a T-matrix scattering algorithm (Mishchenko et al., 1996) that estimates the hydrometeors radar reflectivity for radar frequencies of interest. The idea is then to compare the disdrometer-derived radar reflectivity estimates to the reflectivity observed by the radar at the same height and use their difference to calibrate the radar measurement across the entire atmospheric column. Additional steps arise from the fact that radars generally do not collect measurements down to surface level where disdrometers are located. The several hundred-meter path between these measurements results in three sources of systematic calibration error that can be addressed: (1) radar signal attenuation by atmospheric gases present in the path, (2) radar signal attenuation by the raindrops present in the path and (3) a time lag reflecting the time it takes raindrops to fall from the observed height to the surface. Changes in the particle size distribution due to processes like evaporation and collision-coalescence may also occur, but since these changes are nearly impossible to quantify, they remain a source of uncertainty. The first three effects can be corrected for before comparing radar reflectivity observed at the lowest observation height to the disdrometerderived radar reflectivity estimates. The technique described in the previous section can be used to correct for gas attenuation along the path. Liquid attenuation can be estimated using a T-matrix scattering algorithm and Parsivel ${ }^{2}$ PSD measurements assuming that the PSD remains constant along the path between the radar's lowest observation height and the surface; the lengths of this path are $355 \mathrm{~m}$ for KASPR, ROGER, and VIPR and $1250 \mathrm{~m}$ for SKYLER. Then, time-series analysis can be used to correct for the time lag between the corrected radar reflectivity (from the radar at the lowest observation height) and the disdrometer-derived radar reflectivity estimates.

For this analysis, Parsivel ${ }^{2}$ measurements collected between 17:53-24:00 UTC are used to calibrate the measurements from all four radars. Because of uncertainties in Parsivel $^{2}$ PSD measurements (Tokay et al., 2014), only rain PSDs with mean diameter greater or equal to $0.6 \mathrm{~mm}$ are considered for the calibration procedure (refer to Fig. 3a for details). The median difference between the disdrometerderived and radar-derived (corrected for gas and liquid attenuation and time lag) radar reflectivity over the rain episodes was used to calibrate the entire radar data record collected on that day. The resulting calibration coefficients amount to $-8.1,+0.2,-2.3$, and $+1.3 \mathrm{~dB}$ for SKYLER, KASPR, ROGER, and VIPR, respectively. The small calibration coefficients found for VIPR and KASPR also suggest that the 

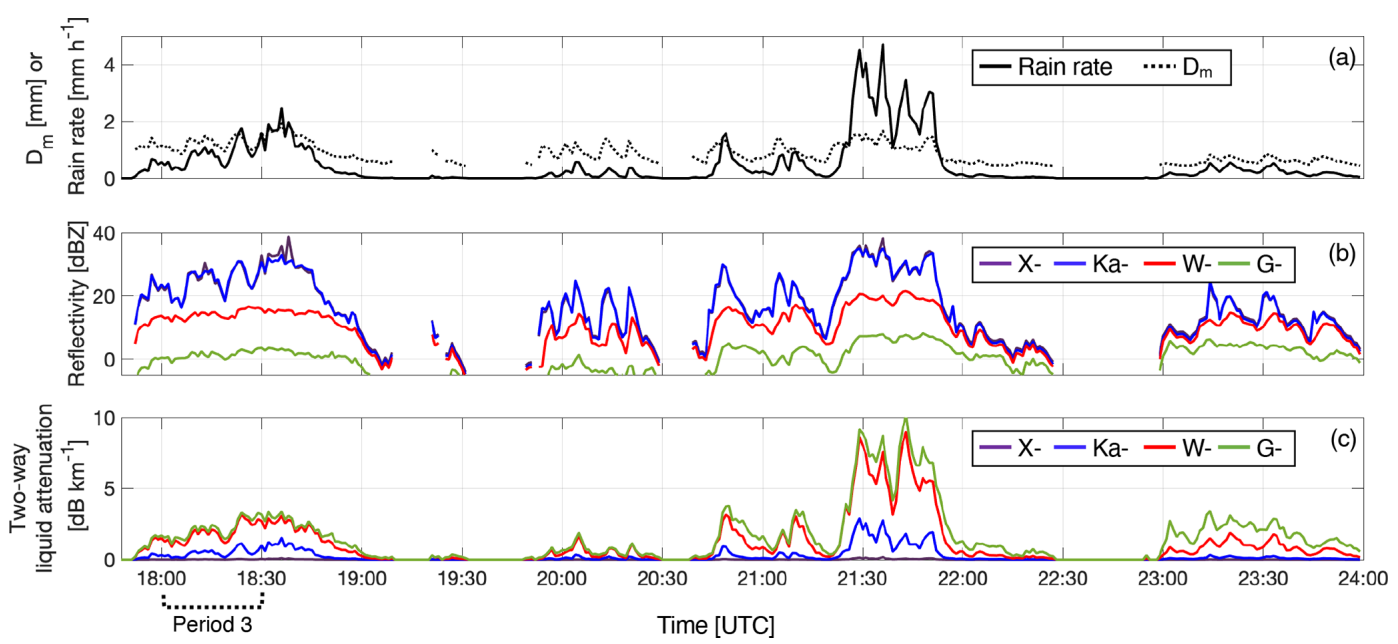

Figure 3. Based on measurements from the Parsivel ${ }^{2}$ disdrometer collected on 25 February 2020, time series of estimated (a) particle size distribution mass-weighted mean diameter ( $D_{\mathrm{m}}$; dotted line) and rain rate (solid line), (b) radar reflectivity, and (c) two-way liquid attenuation for X-band (purple), Ka-band (blue), W-band (red), and G-band (green) signals.

target and corner reflector calibration procedures performed for these radars were reasonably effective.

\subsection{Multifrequency analysis}

Ideally, multifrequency analysis would be performed using perfectly time-matched and volume-matched observations in order to be able to attribute any signal differential to the properties of the hydrometeor population. Unfortunately, previous work has shown that perfectly matching radar observations is extremely challenging even for radars installed on the same pedestal (Kollias et al., 2014). Observation volume differences unavoidably occur as a result of using different radar frequencies, which require the use of different transmitting configurations such as pulse width, pulse repetition frequency and number of samples for integration. Temporal and vertical averaging of radar data on a common grid has been used in an attempt to alleviate radar observation mismatching.

Here we co-gridded the post-processed radar observations from all four radars on a joint $15 \mathrm{~m}, 4 \mathrm{~s}$ resolution grid. The gridded observations are subsequently averaged in time in $60 \mathrm{~s}$ increments to reduce noise. The denoised radar observations are used to estimate the dual-wavelength ratio $\left(D_{\mathrm{W}} \mathrm{R}_{\mathrm{A}-\mathrm{B}}=\mathrm{dBZ}_{\mathrm{A}}-\mathrm{dBZ}_{\mathrm{B}}\right.$, in $\left.\mathrm{dB}\right)$ for three pairs of observed radar reflectivity (Ka-W, Ka-G and $\mathrm{W}-\mathrm{G})$.

\section{Key findings from the multifrequency radar deployment}

On 25 February 2020, following the movement of a surface trough and associated low-pressure system, a stationary front established itself over the SBRO. The four profiling radar systems and the two lidar systems operating at the time ob- served the transition from prefrontal cirrus to rain associated with this system. The following sections discuss key findings attributable to the deployment of a G-band radar as part of a multifrequency radar deployment in these two weather regimes.

\subsection{Using G-band for ice crystals sizing and habit characterization}

The radar and lidar observations displayed in Fig. 4 reveal that a deck of prefrontal cirrus clouds, whose top extended near 9-10 km, advected over the observatory between 07:00 and 10:00 UTC. Observations from KASPR, ROGER and VIPR show that the thickness of the cirrus layer varied over time between $\sim 2$ and $6 \mathrm{~km}$ in depth. In the lowest part of the cloud layer, moderate lidar backscatter signals $\left(\sim 10^{-4.2} \mathrm{~m}^{-1} \mathrm{sr}^{-1}\right)$ suggest the presence of high number concentrations of small particles. Thin bands of high lidar backscatter signals $\left(\sim 10^{-3} \mathrm{~m}^{-1} \mathrm{sr}^{-1}\right)$ near 3.0 and $4.0 \mathrm{~km}$ support the idea that supercooled liquid layers were also present in the lowest part of this cloud system certainly in the earlier and later parts of the period, and likely over the entire period (Fig. 4e). If so, interaction with supercooled liquid could have influenced the ice particle growth processes in the atmospheric column. The mean Doppler velocity recorded by KASPR offers additional insights into the complex dynamical and microphysical structure of the observed layer (Fig. 4d). The signature of a gravity wave with an air velocity of $0.3-0.4 \mathrm{~m} \mathrm{~s}^{-1}$ and a period of 5-6 min is clearly evident throughout the hydrometeor layer. Several, higher-frequency dynamical features are also identifiable in what appears like mammatus cloud features in the lowest $2 \mathrm{~km}$ of the system between 08:45-09:15 UTC. 
(a) Ka-band radar reflectivity from KASPR

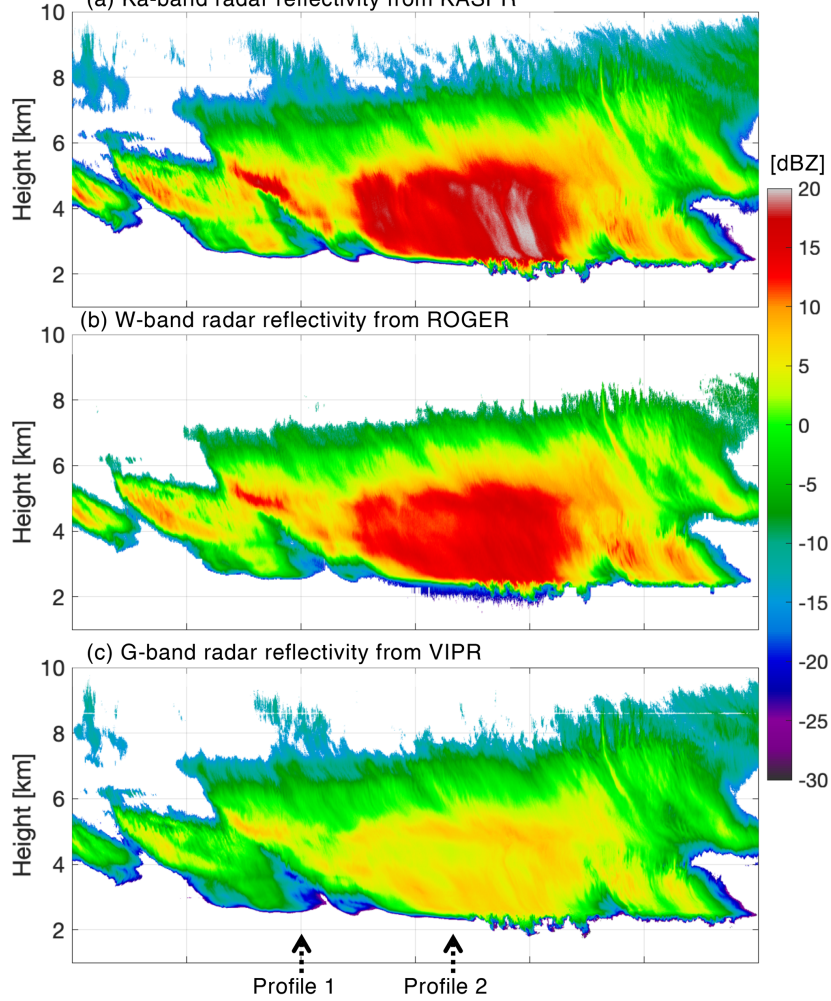

10 (d) Ka-band mean Doppler velocity from KASPR

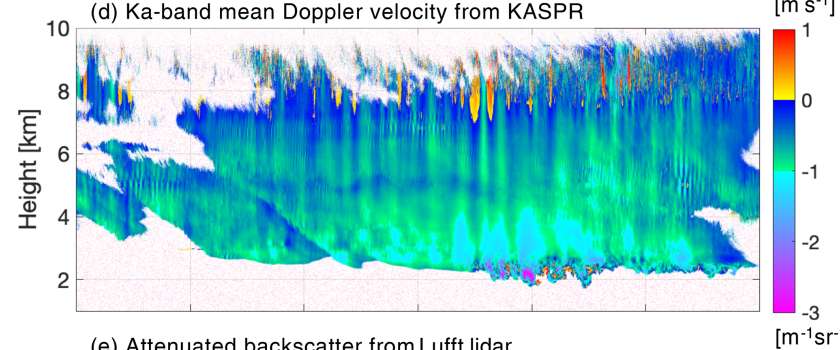

(e) Attenuated backscatter from Lufft lidar

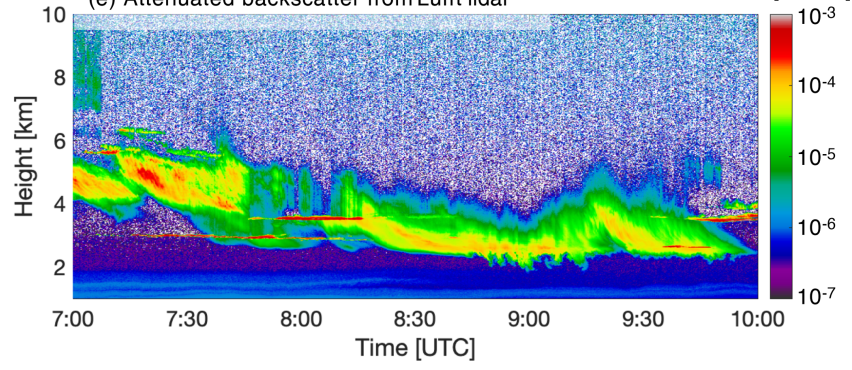

Figure 4. Time-height of radar reflectivity measured by (a) KASPR, (b) ROGER and (c) VIPR, between 07:00 and 10:00 UTC on 25 February 2020. The arrows in panel (c) point to the time of the profiles displayed in Fig. 6. Also shown are time-height data of (d) mean Doppler velocity measured by KASPR (positive values indicate upward motion) and (e) attenuated backscatter measured by the Lufft lidar.

Differences in radar reflectivity measured by the Ka(Fig. 4a), W- (Fig. 4b) and G-band (Fig. 4c) radars are a direct result of differences in signal attenuation and scattering, which can be best visualized in dual-wavelength ratio (DWR)
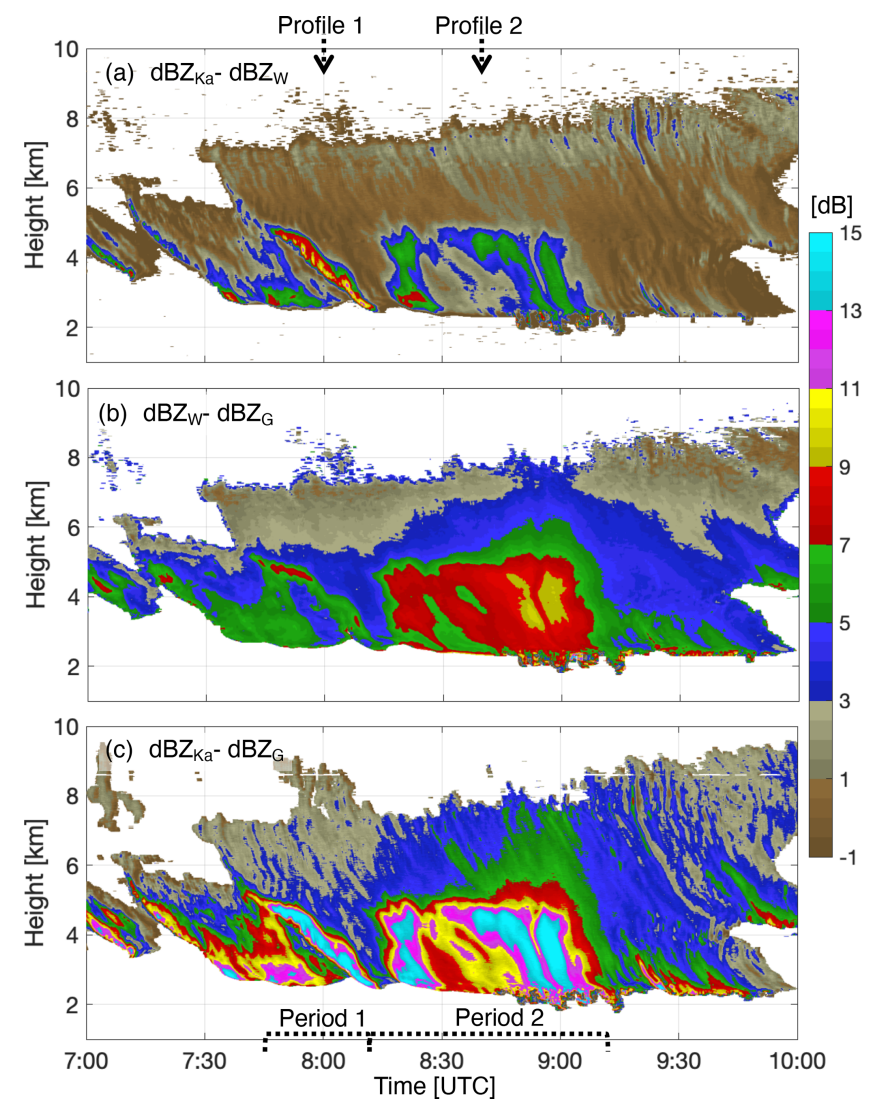

Figure 5. Time-height of dual-wavelength ratio from (a) the $\mathrm{Ka}-$ $\mathrm{W}$ pair, (b) the $\mathrm{W}-\mathrm{G}$ pair and (c) the Ka-G pair estimated between 07:00 and 10:00 UTC on 25 February 2020 (same date and time as in Fig. 4). The arrows in panel (a) point to the time of the profiles displayed in Fig. 6, while the periods outlined in panel (c) are the focus of Fig. 7.

space. Figure 5 shows DWR estimated using the traditional $\mathrm{Ka}-\mathrm{W}$ pair (panel a), the W-G pair (panel b) and the KaG pair (panel c). These first light DWR observations involving G-band confirm all the advantages predicted by scattering theory.

Focusing below $\sim 4.5 \mathrm{~km}$, we observe that in contrast to the Ka-W pair (Fig. 5a), the frequency pairs with G-band (Fig. 5b-c) indeed experience larger differential signals for the same hydrometeor population; for the case observed, the DWR profile shown in Fig. $6 \mathrm{~b}$ allows us to estimate that this gain was as large as $\sim 4 \mathrm{~dB}$ for the $\mathrm{Ka}-\mathrm{G}$ pair in comparison to the $\mathrm{Ka}-\mathrm{W}$ pair. This increased dynamic range in DWRs corresponds to an increased sensitivity in the transfer function between DWRs and microphysical properties. This underpins the value of using frequency pairs farther apart in the frequency spectrum not only to mitigate the impact of possible noise when retrieving the size of smaller particles or lower water mass amounts but also to increase retrieval precision. Finally, observations collected above $4.5 \mathrm{~km}$ reveal the G-band's strength in small particle regimes. In this region, 

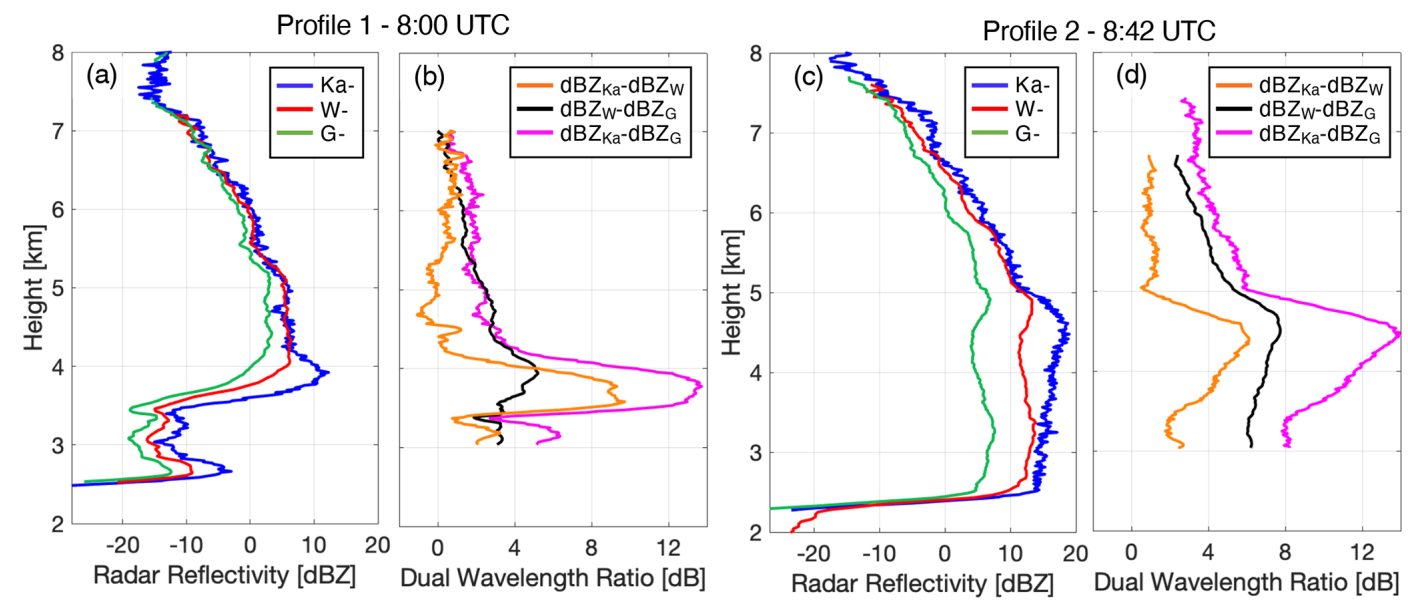

Figure 6. Profiles taken at 08:00 UTC during the ice cloud period, (a) radar reflectivity measured by VIPR (G-band, green), ROGER (Wband, red) and KASPR (Ka-band, blue) and (b) associated dual-wavelength ratio from the Ka-W pair (orange), the W-G pair (black) and the $\mathrm{Ka}-\mathrm{G}$ pair (magenta). Panels (c) and (d) show the same information for the profile taken at 08:42 UTC.

absence of Ka-W differential signal (i.e., DWR $=0 \mathrm{~dB}$ ) suggests the presence of Rayleigh targets (Tridon et al., 2020). At these frequencies Rayleigh targets correspond to ice populations with PSDs of mass-weighted mean diameter smaller than $\sim 1 \mathrm{~mm}$ (Tridon et al., 2019). The absence of differential scattering signals in the Ka-W band prevents us from gaining further information about such small ice crystals. On the other hand, the presence of differential signal in the $\mathrm{Ka}-\mathrm{G}$ band and $\mathrm{W}-\mathrm{G}$ band on the order of a few decibels across most of the layer (see Figs. 5b-c and 6b) supports that DWR estimates that use G-band signals can provide size information about smaller ice crystals.

Interpreting and performing retrievals from DWR observations always requires considering the interplay of signal attenuation and non-Rayleigh scattering (Tridon et al., 2013). Observations collected during the period around 08:42 UTC highlight this important limitation of DWR analysis targeting the characterization of ice crystals. The lack of convergence at $0 \mathrm{~dB}$ in the profile extracted at 08:42 UTC suggests the presence of considerable water condensate (liquid and/or ice) mass in the atmospheric column (Fig. 6d). Backscatter lidar observations do allude to the presence of liquid layers (of unknown depth) over that period (Fig. 4e). Tridon et al. (2020) suggest that if DWR reaches a constant value with height (a.k.a. a Rayleigh plateau), the DWR of this plateau can be used to estimate integrated water condensate mass within the layer. In this particular profile, the $\mathrm{Ka}-\mathrm{W}$ pair reached a clear Rayleigh plateau at $5 \mathrm{~km}$ showing a $1 \mathrm{~dB}$ DWR loss to hydrometeor attenuation. We argue that both the $\mathrm{Ka}-\mathrm{G}$ pair and the $\mathrm{W}-\mathrm{G}$ pair also reached a Rayleigh plateau near $6.8 \mathrm{~km}$ showing in the neighborhood of $3.5 \mathrm{~dB}$ DWR loss to hydrometeor attenuation. This signal could be qualified as being the first quantitative hydrometeor mass signal recorded at G-band. Because ice and snow attenuation considerably increase when moving from the $\mathrm{W}$ - to the G-band reaching one-way values of $0.9,2.5$, and $8.7 \mathrm{~dB} \mathrm{~m}^{2} \mathrm{~kg}^{-1}$ at 96,140 , and $225 \mathrm{GHz}$, respectively (Tridon et al., 2020; Nemarich et al., 1988), the DWR plateau for the G-band pairs is affected by both the liquid water path and the ice water path. On the other hand, the DWR plateau for the Ka-W pair is mainly driven by the liquid water path. We believe that the shallowness of the W-G band plateau results from the limited sensitivity of ROGER, which is likely insufficient to detect additional Rayleigh targets populating at the top of the ice cloud. This observation supports the need for developing highly sensitive radars when targeting small (in size) hydrometeor populations. Unfortunately, because millimeterwavelength radar signals alone cannot be used to precisely distribute the retrieved water path across the atmospheric column, non-Dopplerized DWR observations in mixed-phased clouds cannot be disentangled to isolate the non-Rayleigh signals required for sizing and identifying ice crystal habit, leaving yet again a gap in our understanding.

The DWR profile shown in Fig. $6 \mathrm{~b}$ taken from observations collected at 08:00 UTC shows a contrasting situation where G-band signals can be directly used for ice microphysical retrievals. In that profile DWR is seen to converge to $0 \mathrm{~dB}$ such that differential signal across the column can be interpreted from resulting exclusively from non-Rayleigh scattering. Under such conditions DWR can be related to ice crystal size given the proper ice scattering library. Kneifel et al. (2015) initially proposed using DWR $_{\mathrm{X}-\mathrm{Ka}}$ versus $\mathrm{DWR}_{\mathrm{Ka}-\mathrm{W}}$ diagrams to identify ice particle types from multiwavelength radar observations. Recently, it has become evident that details of the PSDs and unaccounted attenuation complicate the analysis of such diagrams that must be interpreted with caution (Battaglia et al., 2020). Figure 7 shows the distribution of DWR Ka-W versus DWR $\mathrm{W}_{\mathrm{W}-\mathrm{G}}$ diagrams for two periods encompassing the profiles described above. Overlaid are $\mathrm{DWR}_{\mathrm{Ka}-\mathrm{W}}-\mathrm{DWR}_{\mathrm{W}-\mathrm{G}}$ 

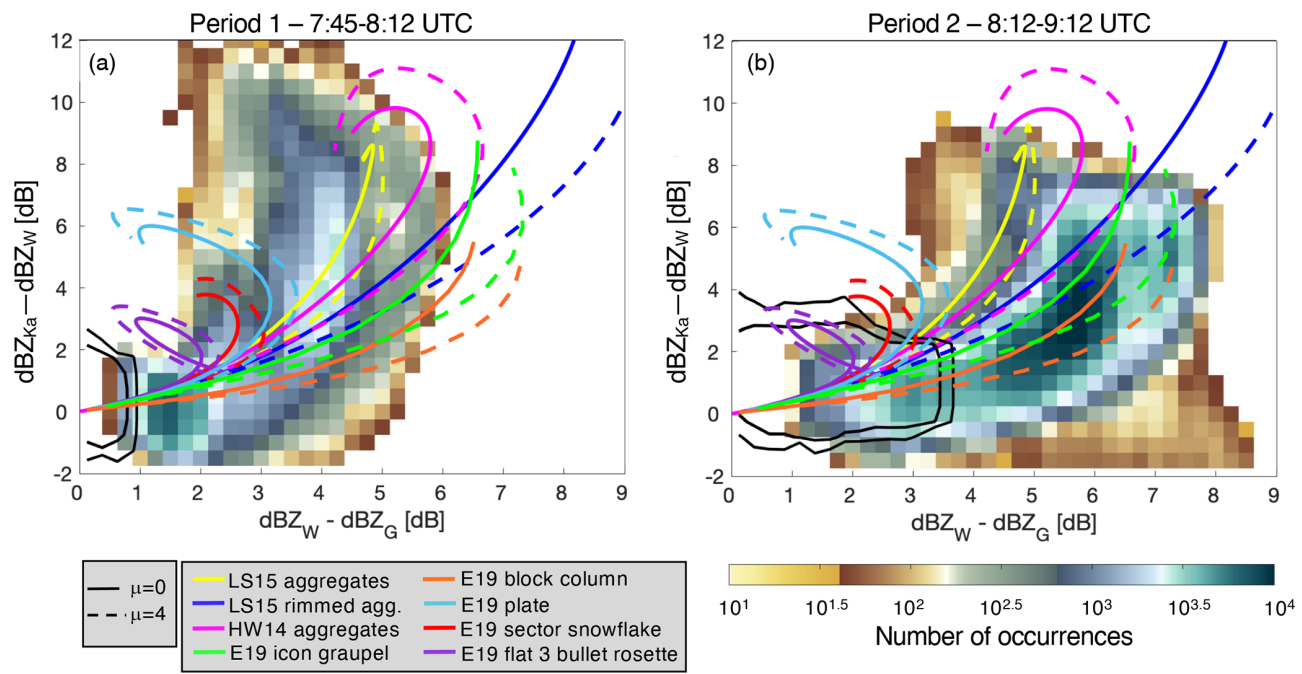

Figure 7. For observations collected (a) between 07:45-08:12 UTC and (b) between 08:12-09:12 UTC; distribution of Ka-W dualwavelength ratio as a function of $\mathrm{W}-\mathrm{G}$ dual-wavelength ratio for the cloud region between 2 and $5.5 \mathrm{~km}$ altitude (color map) and for the cloud region between 5.75 and $7 \mathrm{~km}$ altitude (contours). Lines represent effective reflectivity calculated using scattering models with different particle type (colors) and with different particle size distribution shape parameter (line type). More details about these scattering models are given in the text.

lines estimated using self-similar Rayleigh-Gans approximation and different particle type models; specifically, unrimed aggregates are represented using the mass-diameter relationships from Hogan and Westbrook (2014) (hereafter HW14) and that of Leinonen and Szyrmer (2015) (hereafter LS15) particle class A. Rimed aggregates are represented using the mass-diameter relationships of LS15 for particle type B with $2 \mathrm{~kg} \mathrm{~m}^{-2}$ of liquid water path. Also overlaid are $\mathrm{DWR}_{\mathrm{Ka}-\mathrm{W}}-\mathrm{DWR} \mathrm{R}_{\mathrm{W}-\mathrm{G}}$ lines estimated using discrete dipole approximation scattering calculations for different particle types following the formulation prepared by Eriksson et al. (2018) (hereafter E19); specifically, icon graupel, block column, plate, sector snowflake and flat three-bullet rosette. Since the shape of the PSD may also impact the scattering of the ice crystal population, PSDs are represented using a gamma function with a shape parameter $(\mu)$ of either 0 or 4. We acknowledge that this does not encompass all PSD shapes such as the super exponential one of aggregate populations reported by Westbrook et al. (2004). In any case, the idea is to use overlap between the observed and estimated DWR-DWR to gain information about particle habit.

The first period (07:45-08:12 UTC) depicted in Fig. 7a corresponds to the period that presented a high-DWR slanted feature (referring back to Fig. 5) and a thin liquid layer (referring back to the lidar backscatter observations of Fig. 4). Plotting the radar observations in DWR-DWR space can help determine if the amount of liquid attenuation caused by this thin liquid layer is significant thus preventing us from inferring particle habit directly from the gas attenuation corrected and calibrated radar measurements. To be exact, a clustering of the DWR-DWR observations collected in the upper part of the cloud (between $5.750-7.00 \mathrm{~km}$ ) near the 0,0 point would indicate an absence of signal attenuation. For this particular period, a $0.5 \mathrm{~dB}$ offset is seen in the contours on Fig. 7a, suggesting that a slight adjustment should be made to the observed DWR before they can be interpreted in terms of differential scattering and used to infer particle habit. Even with this slight adjustment, we find that the scattering calculation results only partially match the DWR-DWR signatures observed leaving a noticeable gap in the high $(>7 \mathrm{~dB})$ DWR $_{\mathrm{Ka}-\mathrm{W}}$ and low $(<5 \mathrm{~dB}) \mathrm{DWR}_{\mathrm{W}-\mathrm{G}}$ region. This gap could result from outstanding radar calibration bias or from a misrepresentation of the particle size distribution and/or shape of naturally occurring ice crystal in existing scattering libraries. In any case, it calls for further research. We note that the scattering models that are closest to the observed values are those for unrimed aggregates (yellow and magenta lines) and plates (cyan line). In an attempt to further characterize these ice crystals, we note that the sounding reported a temperature in the region of roughly $-15^{\circ} \mathrm{C}$ and relative humidity of roughly $80 \%$ (referring to Fig. 2). Under such thermodynamic conditions, high-DWR $\mathrm{Ka}-\mathrm{W}$ values are typically associated with the presence of dendritic crystals and aggregates (e.g., Bechini et al., 2013; Andrić et al., 2013). Based on the velocity of the primary peak in the KASPR Doppler spectra over the period, we estimate the fall speed of the ice particles to be roughly $0.8 \mathrm{~m} \mathrm{~s}^{-1}$. These slow fall speeds would be consistent with the presence of unrimed particles; something that is also in line with our conclusion that this period did not present significant amounts of supercooled liquid. Altogether the large DWR values and the low 
terminal velocity suggest the presence of large and fluffy, unrimed particles (Locatelli and Hobbs, 1974).

The second period (08:12-09:12 UTC) depicted in Fig. 7b corresponds to the period containing non-negligible attenuation by water condensates. This period also presents a broad high-DWR area between 2 and $5.5 \mathrm{~km}$ altitude (referring back to Fig. 5). The offset from $0,0 \mathrm{DWR}_{\mathrm{Ka}-\mathrm{W}}-\mathrm{DWR} \mathrm{W}-\mathrm{G}$ of observations collected between $5.75-7.00 \mathrm{~km}$ can also be used to confirm the presence of water condensates (depicted by the contours in Fig. 7b). Although tempting, it is not possible to directly interpret this DWR-DWR diagram since details about the vertical distribution of the liquid and ice water content is not known and as such attenuation cannot be accurately corrected for. Based on the velocity of the primary peak in the KASPR Doppler spectra over the period, we estimate the fall speed of the ice particles to be roughly $1.3 \mathrm{~m} \mathrm{~s}^{-1}$. Such faster fall speeds would be consistent with the presence of rimed particles; something that is also in line with our conclusion that this period presented significant amounts of supercooled liquid.

\subsection{Using G-band for characterizing melting and sizing sub-millimeter drizzle droplets}

The radar observations displayed in Fig. 8 show the light surface rain episode that occurred following the frontal passage between 18:00 and 18:30 UTC. Observations from KASPR allow us to establish that the cloud sustaining the rain extended up to $8 \mathrm{~km}$. The bright band observed by all radars, although notably different, is suggestive of a transition from ice particle to liquid water near $2 \mathrm{~km}$. This idea is substantiated by radiosonde reports that place the $0^{\circ}$ isotherm near $2 \mathrm{~km}$ (Fig. 2a). Surface disdrometer measurements indicate that rainfall rate at the surface varied reaching up to $2.1 \mathrm{~mm} \mathrm{~h}^{-1}$ during the period (Fig. 3a within the limits of period 3). From time-lag estimates performed as part of the calibration procedure, we estimate that the raindrop fall speeds ranged from 3 to $6 \mathrm{~m} \mathrm{~s}^{-1}$. These estimates are consistent with KASPR mean Doppler velocity measurement made during the period (not shown).

Difference in radar reflectivity measured by the $\mathrm{X}$ (Fig. 8a), Ka- (Fig. 8b), W- (Fig. 8c) and G-band (Fig. 8d) radars during the period and specifically at 18:07 UTC (Fig. 9a) are a direct result of difference in signal attenuation and scattering.

Differential signal scattering explains the progressive reduction in the overall radar reflectivity factor measured by the X-band SKYLER, Ka-band KASPR, W-band ROGER and G-band VIPR. During this light rain period, we expect the $3.2 \mathrm{~cm}$ wavelength X-band signal to experience Rayleigh scattering; especially considering the range of particle diameters measured by the disdrometer (Fig. 3a). In the Rayleigh scattering regime, radar backscattering cross section $\left(\sigma_{\mathrm{b}}\right)$ is proportional to $D^{6} / \lambda^{4}$, where $D$ is particle diameter. Because wavelength is much larger than particle diameter, $\sigma_{\mathrm{b}}$ tends to

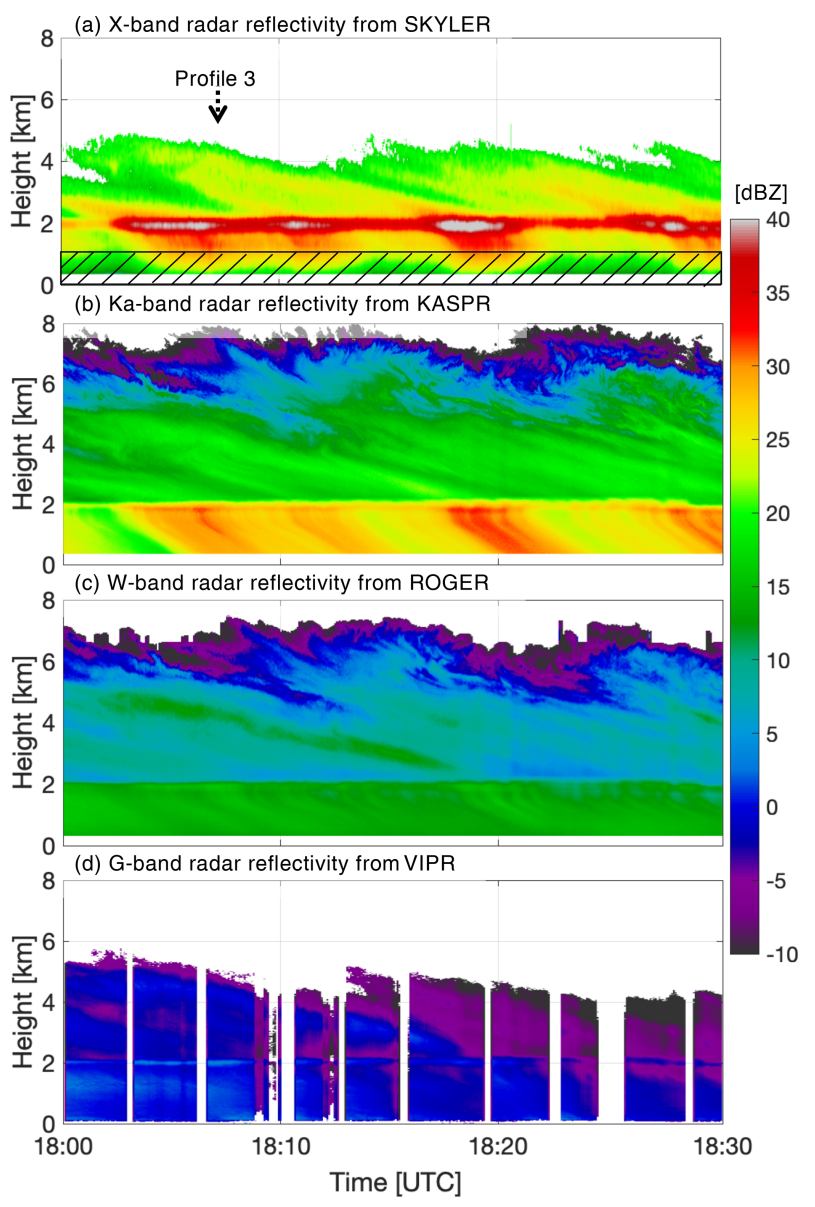

Figure 8. Time-height of radar reflectivity measured by (a) SKYLER, (b) KASPR, (c) ROGER and (d) VIPR between 18:00 and 18:30 UTC on 25 February 2020. Observations covered by the hatching in panel (a) are known to be biased low because of a human error in setting the radar receiver blanking parameters. The arrow in panel (a) points to the time of the profile displayed in Fig. 9.

be very small in that regime. That being said, the radar reflectivity factor $(Z)$, which was designed to compensate for the wavelength dependency, can acquire very high values in that scattering regime $\left(Z \sim D^{6}\right)$. In contrast to X-band signals, Ka-, W- and G-band signals are expected to experience both Rayleigh scattering (for drops smaller in size relative to the wavelength) and non-Rayleigh scattering (for drops larger in size relative to the wavelength). In the non-Rayleigh scattering regime, $\sigma_{\mathrm{b}}$ does not monotonically increase with $D^{6}$ but rather follows a lower power resonance pattern with damping of the oscillation (Fig. 4 of Kollias et al., 2007a). As a result, although in non-Rayleigh scattering $\sigma_{\mathrm{b}}$ acquires much higher values than those in Rayleigh scattering, the reported radar reflectivity factor during non-Rayleigh conditions is lower. Variations in each of the radars' "dominant" drop population (i.e., the largest drop size behaving as a Rayleigh scatterer) also explains variations in the ob- 

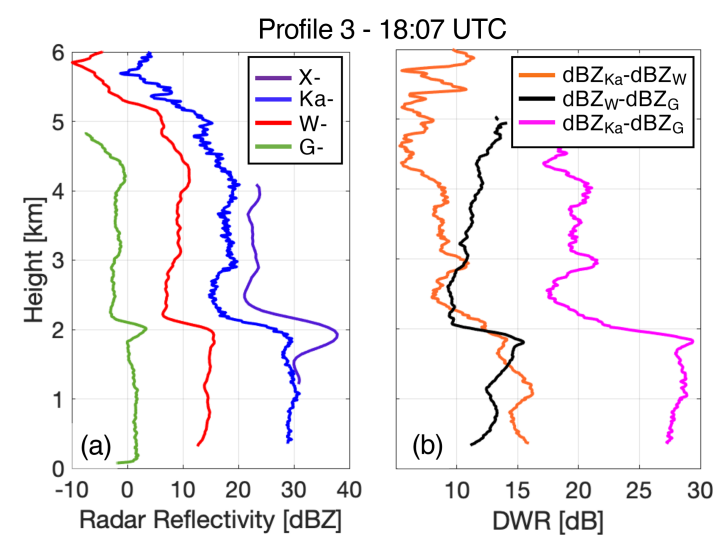

Figure 9. Profiles taken at 18:07 UTC during the rain period; (a) radar reflectivity measured by VIPR (G-band, green), ROGER (W-band, red), KASPR (Ka-band, blue) and SKYLER (X-band, purple) and (b) associated dual-wavelength ratio from the $\mathrm{Ka}-\mathrm{W}$ pair (orange), the $\mathrm{W}-\mathrm{G}$ pair (black) and the $\mathrm{Ka}-\mathrm{G}$ pair (magenta).

served radar bright band. SKYLER, like a typical centimeter wavelength radar, observed a bright band marked by clear boundaries at both the top and the bottom. Inferring information about the ice-melting process from the properties of the radar-detected bright band is still an active area of research (e.g., Heymsfield et al., 2015; Li et al., 2020). The early work of Fabry and Zawadzki (1995) suggested that the magnitude and vertical extent of the radar reflectivity enhancement at centimeter-wavelength radars are influenced by precipitation rate, phase transitions (i.e., liquid coating ice), change in fall speed throughout melting, precipitation growth and changes in the particle size distribution linked to aggregation and breakup. More recent studies suggested that the depth of the radar bright band, at centimeter wavelengths, may be linked to the presence of rimed particles (e.g., Kumjian et al., 2016; Wolfensberger et al., 2016). In contrast, at millimeterwavelength radars, non-Rayleigh scattering reduces the influence of large melting snowflakes in determining the magnitude and vertical extent of the melting layer radar signature (Kollias and Albrecht, 2005). In addition, due to their increased relative sensitivity to small melting ice crystals, millimeter-wavelength radars like KASPR and ROGER observe a higher top boundary of their bright band. While not observed here, it has been suggested that W-band radars can provide insight into the activity of the aggregation process, because this process is believed to cause a dip, as opposed to the enhancement that is the bright band, in the radar reflectivity profile (a.k.a. dark band; Sassen et al., 2005, 2007; Heymsfield et al., 2008). Interestingly, observations collected by VIPR reveal a well-defined bright band at G-band frequencies. VIPR's bright band differs from that of the other radars in two main ways: (1) its top boundary is slightly higher compared to that of the W-band, and (2) its bottom boundary is higher than that of the X-band. These discrepancies are in line with our interpretation that VIPR's signal is controlled by the melting of even smaller ice crystals. This agrees with the interpretation by $\mathrm{Li}$ and Moisseev (2020) that the radar bright band properties depend on the radar wavelength since the radar wavelength effectively dictates the ice population size "in focus". We should also note that part of this discrepancy could be explained by the fact that our Xband SKYLER has a much larger range resolution than our G-band VIPR ( $300 \mathrm{~m}$ vs. $15 \mathrm{~m}$ ).

Although G-band signals should allow for sizing smaller raindrops since they experience non-Rayleigh scattering at smaller droplets sizes (compared to longer wavelengths), one must remember that G-band signals also experience nonnegligible liquid attenuation. Theoretical calculations suggest that extinction coefficients at 94 and $220 \mathrm{GHz}$ rapidly increase for particles with size up to $D_{\mathrm{m}} \approx 1$ and $0.4 \mathrm{~mm}$, respectively, and then steadily decrease as a function of $D_{\mathrm{m}}$ (Lhermitte, 1990). For the duration of the observed rain event, we estimate (from disdrometer PSD measurements) that two-way liquid attenuation of the G-band signal varied from 0 to $10 \mathrm{~dB}$ (Fig. 3c). While non-negligible, this value is only about 2.2 times (in linear scale) higher than that experienced by a W-band radar like ROGER or the CloudSatCPR (Fig. 3c; Battaglia et al., 2014). As seen in Fig. 8 both ROGER and VIPR were both equally able to penetrate through the $2 \mathrm{~km}$ thick rain layer and detect a large portion of the cloud aloft (Fig. 8c and d respectively). The fact that VIPR and ROGER could not observe the cloud top speaks to the importance of operating highly sensitive G-band and W-band radars especially if they are meant to document the properties of liquid precipitating clouds. The other fact that SKYLER could also not observe the cloud top speaks to the importance of operating sensitive X-band radars for cloud studies (liquid attenuation not being an issue at centimeter wavelengths).

Like we saw in ice clouds, large $\mathrm{DWR}_{\mathrm{Ka}-\mathrm{G}}$ and $\mathrm{DWR} \mathrm{R}_{\mathrm{W}-\mathrm{G}}$ signals were measured during the rain event (Fig. 9b); in this example profile collected at 18:07 UTC, DWR $\mathrm{Ka}-\mathrm{G}_{\text {reached }}$ values as high as $30 \mathrm{~dB}$. Interpreting these signals requires separating the contributions of liquid attenuation and nonRayleigh scattering. In regimes with large $D_{\mathrm{m}}(>1 \mathrm{~mm})$, similar liquid attenuation at W- and G-band should allow for the interpretation of DWR $\mathrm{W}_{\mathrm{W}}$ signals in terms of differential scattering caused by liquid drops (that is when gas attenuation has been corrected for). Such interpretation is arguably more challenging using the $\mathrm{Ka}-\mathrm{W}$ or the $\mathrm{Ka}-\mathrm{G}$ frequency pairs (Matrosov, 2005).

\section{Conclusions}

Several gaps in cloud and precipitation remote sensing still exist especially at mid and high latitudes (Battaglia et al., 2020). Radars at frequencies above $100 \mathrm{GHz}$ are now technologically feasible as proved by the VIPR system recently built by JPL. This work presents multifrequency (X-, Ka-, 
W- and G-band) radar observations from a field experiment at the Stony Brook Radar Observatory (SBRO). Albeit short, the field experiment provided a long-sought-after first light demonstration of the potential of multiwavelength radar observations that include G-band for the characterization of ice crystals, snow and rain. Besides confirming expectations derived from scattering theory, the field experiment revealed a number of considerations relevant to the deployment of Gband systems.

1. The observations clearly demonstrate that G-band radars can be made sensitive enough to probe clouds and light precipitation in spite of the strong water vapor attenuation occurring at this frequency. The large sensitivity of G-band radars can in part be explained by improvements in radar gain with increased frequency; all else equal, for a fixed aperture size, radar sensitivity improves by $24 \mathrm{~dB}$ going from 10 to $170 \mathrm{GHz}$.

2. Since G-band signals are especially prone to attenuation by water vapor, we recommend that G-band radars targeting the characterization of clouds and precipitation should have differential absorption capabilities in order to avoid confounding effects due to water vapor attenuation. This could be achieved through the use of interlaced pulses whose frequency would range around a water vapor absorption line. The exact frequency range should ideally be tuned to the specific water vapor condition like those proposed in Roy et al. (2020), Cooper et al. (2020), and Battaglia and Kollias (2019).

The observations presented here reinforce the idea that the sensitivity of all the radar systems involved in future multiwavelength radar studies should be sufficient to allow the detection of the Rayleigh plateau near the top of ice clouds (or near the base if using an airborne system); that is necessary to ensure that we have a robust estimation of the differential (dual-wavelength) pathintegrated liquid attenuation (Tridon et al., 2020). For rain studies as well, G-band radar sensitivity should be large enough to allow signals to penetrate through the rain shaft despite attenuation by liquid water reaching several decibels. Nominally radar systems should be capable of detecting unattenuated reflectivity as weak as $-40 \mathrm{dBZ}$ at $1 \mathrm{~km}$ after $1 \mathrm{~s}$ signal integration (i.e., $-20 \mathrm{dBZ}$ at $10 \mathrm{~km}$ altitude). In the present study, the radars deployed generally meet this sensitivity criteria. It follows that deployments in humid environments would drive higher sensitivity requirements because of enhanced signal attenuation by water vapor. The same can be said about deployments that target liquidcontaining clouds where enhanced signal attenuation by liquid water is to be expected.

3. The observations collected during this experiment confirm that the $\mathrm{Ka}-\mathrm{G}$ pair generates the strongest differential reflectivity signal, with observed values of DWR reaching up to $13 \mathrm{~dB}$ in ice regions, which is $4 \mathrm{~dB}$ larger than traditionally $\mathrm{Ka}-\mathrm{W}$ pairs. The increased differential signal should allow for increased retrieval confidence, especially in low-liquid-water-content regions and/or for small particle sizes.

4. The steep DWR $\mathrm{Ka}_{\mathrm{a}-\mathrm{G}}$ gradients observed support the idea that $\mathrm{Ka}-\mathrm{G}$ differential signals are more sensitive to incremental changes in particle size, thus allowing for more precise quantitative retrievals compared to those achievable using a $\mathrm{Ka}-\mathrm{W}$ pair.

5. In the absence of Ka-W differential signals, observations of non-Rayleigh differential scattering signals at $\mathrm{Ka}-\mathrm{G}$ and $\mathrm{W}-\mathrm{G}$ demonstrates the potential of G-band radars for sizing smaller ice particles.

6. An ideal case observed during the field experiment allowed us to investigate ice crystal habit. DWR-DWR observed by the Ka-W-G trio were compared to estimates made using several scattering libraries. The scattering libraries tested could only provide a partial explanation of the scattering properties of the ice crystals observed with gaps in the high $(>7 \mathrm{~dB})$ DWR $_{\mathrm{Ka}-\mathrm{W}}$ and low $(<5 \mathrm{~dB}) \mathrm{DWR}_{\mathrm{W}-\mathrm{G}}$ region. This gap could result from outstanding radar calibration bias or from a misrepresentation of the particle size distribution and/or shape of naturally occurring ice crystal; in any case additional triple-frequency observations including the Gband would help confirm this finding, which, if correct, should motivate further research into the scattering properties of naturally occurring ice crystal populations.

7. The observations collected during a melting event suggest that G-band radars can detect radar bright bands. The character of this bright band is likely indicative of the melting behavior of smaller ice crystals.

8. In rain, the G-band radar reflectivity values are several orders of magnitude lower than those measured by the W-band, Ka-band and X-band radar systems creating measurable DWR signal. Interpreting these differential signals may be challenging, because they result from both differential scattering and attenuation. In large particle regimes where $\mathrm{W}$ - and G-band signals experience similar attenuation by liquid, $\mathrm{DWR}_{\mathrm{W}-\mathrm{G}}$ should provide information more closely related to the massweighted diameter of the particle size distribution. Ideally full Doppler spectrum capabilities should be added to G-band radars, especially for applications in rain and mixed-phase clouds. Doppler capability would allow for application of spectral ratio techniques like proposed in Tridon et al. (2013).

Longer datasets with similar measurement capabilities are needed to fully assess the potential and challenges associated with using non-Dopplerized G-band radar observations 
for the study of clouds and precipitation systems. Such observations can in turn be used to raise the technology and science readiness levels of spaceborne G-band systems. G-band radar signals coming from an above-cloud vantage point should suffer from less signal attenuation than ground-based systems; that is because water vapor and rain are typically concentrated in the lowest part of the atmosphere. The reduced signal attenuation for airborne and spaceborne G-band radars should drive a less stringent sensitivity requirement $(-20 \mathrm{dBZ}$ in the troposphere after signal integration of $1 / 2$ of the radar footprint).

Data availability. The datasets collected at the SBRO during the field experiment are available at https://commons.library. stonybrook.edu/somasdata/12/ (Oue and Lamer, 2021). The US NWS sounding data are available at https://www.spc.noaa.gov/ exper/soundings/ (Hart and Thompson, 2021).

Author contributions. KL, MO, AB, RJR, KBC and PK were actively involved in the field experiment; KL operated the Doppler lidar, MO operated the KASPR, and RJR and KBC together operated VIPR. MO and RD performed initial data exploration work. PK finalized the data analysis. AB's and PK's inputs were instrumental in interpreting the radar signatures observed. KL lead the writing of the final version of this article. All members of the team reviewed and added to this final version.

Competing interests. The authors declare that they have no conflict of interest.

Acknowledgements. This research also used the Advanced Leicester Information and Computational Environment (ALICE) High Performance Computing Facility at the University of Leicester, UK. We would like to thank the Brookhaven National Laboratory staff and Stony Brook University students who assisted during the field experiment; special thanks go to Edward Luke for operating SKYLER and to Zeen Zhu, Samantha Nebylitsa, Jacob Segall and Kristofer Tuftedal for launching radiosondes from the SBRO.

Financial support. This research has been supported by the Brookhaven National Laboratory (LDRD, grant no. 20-002 EE/EBNN), the National Science Foundation (grant no. 1841246), the National Aeronautics and Space Administration (grant no. 80NM0018D0004) and the UK-Centre for Earth Observation Instrumentation under the Grace project.

Review statement. This paper was edited by Stefan Kneifel and reviewed by two anonymous referees.

\section{References}

Andrić, J., Kumjian, M. R., Zrnić, D. S., Straka, J. M., and Melnikov, V. M.: Polarimetric signatures above the melting layer in winter storms: An observational and modeling study, J. Appl. Meteorol. Clim., 52, 682-700, 2013.

Battaglia, A. and Kollias, P.: Evaluation of differential absorption radars in the $183 \mathrm{GHz}$ band for profiling water vapour in ice clouds, Atmos. Meas. Tech., 12, 3335-3349, https://doi.org/10.5194/amt-12-3335-2019, 2019.

Battaglia, A., Westbrook, C. D., Kneifel, S., Kollias, P., Humpage, N., Löhnert, U., Tyynelä, J., and Petty, G. W.: G band atmospheric radars: new frontiers in cloud physics, Atmos. Meas. Tech., 7, 1527-1546, https://doi.org/10.5194/amt-7-1527-2014, 2014.

Battaglia, A., Kollias, P., Dhillon, R., Roy, R., Tanelli, S., Lamer, K., Grecu, M., Lebsock, M., Watters, D., and Mroz, K.: Spaceborne Cloud and Precipitation Radars: Status, Challenges, and Ways Forward, Rev. Geophys., 58, e2019RG000686, https://doi.org/10.1029/2019RG000686, 2020.

Bechini, R., Baldini, L., and Chandrasekar, V.: Polarimetric Radar Observations in the Ice Region of Precipitating Clouds at C-Band and X-Band Radar Frequencies, J. Appl. Meteorol. Clim., 52, 1147-1169, https://doi.org/10.1175/jamc-d-12-055.1, 2013.

Chandrasekar, V., Baldini, L., Bharadwaj, N., and Smith, P. L.: Calibration procedures for global precipitation-measurement groundvalidation radars, URSI Radio Science Bulletin, 355, 45-73, https://doi.org/10.23919/URSIRSB.2015.7909473, 2015.

Cooper, K., Monje, R. R., Millan, L., Lebsock, M., Tanelli, S., Siles, J. V., Lee, C., and Brown, A.: Atmospheric humidity sounding using differential absorption radar near $183 \mathrm{GHz}$, IEEE Geosci. Remote S., 15, 163-167, 2018.

Cooper, K., Roy, R. J., Dengler, R., Monje, R. R., AlonsodelPino, M., Siles, J. V., Yurduseven, O., Parashare, C., Millán, L., and Lebsock, M.: G-Band Radar for Humidity and Cloud Remote Sensing, IEEE T. Geosci. Remote, 59, 11061117, https://doi.org/10.1109/TGRS.2020.2995325, 2020.

Eriksson, P., Ekelund, R., Mendrok, J., Brath, M., Lemke, O., and Buehler, S. A.: A general database of hydrometeor single scattering properties at microwave and submillimetre wavelengths, Earth Syst. Sci. Data, 10, 1301-1326, https://doi.org/10.5194/essd-10-1301-2018, 2018.

Fabry, F. and Zawadzki, I.: Long-term radar observations of the melting layer of precipitation and their interpretation, J. Atmos. Sci., 52, 838-851, 1995.

Hart, J. and Thompson R.: Observed Sounding Archive, NOAA's National Weather Service Storm Prediction Center, available at: https://www.spc.noaa.gov/exper/soundings/, last access: 4 May 2021.

Heymsfield, A. J., Bansemer, A., Matrosov, S., and Tian, L.: The $94 \mathrm{GHz}$ radar dim band: Relevance to ice cloud properties and CloudSat, Geophys. Res. Lett., 35, L03802, https://doi.org/10.1029/2007GL031361, 2008.

Heymsfield, A. J., Bansemer, A., Poellot, M. R., and Wood, N.: Observations of ice microphysics through the melting layer, J. Atmos. Sci., 72, 2902-2928, 2015.

Hogan, R. J. and Illingworth, A. J.: The potential of spaceborne dual-wavelength radar to make global measurements of cirrus clouds, J. Atmos. Ocean. Tech., 16, 518-531, 1999. 
Hogan, R. J. and Westbrook, C. D.: Equation for the microwave backscatter cross section of aggregate snowflakes using the selfsimilar Rayleigh-Gans approximation, J. Atmos. Sci., 71, 32923301, 2014.

Hogan, R. J., Gaussiat, N., and Illingworth, A. J.: Stratocumulus liquid water content from dual-wavelength radar, J. Atmos. Ocean. Tech., 22, 1207-1218, 2005.

Illingworth, A. J., Barker, H., Beljaars, A., Ceccaldi, M., Chepfer, H., Clerbaux, N., Cole, J., Delanoë, J., Domenech, C., and Donovan, D. P.: The EarthCARE satellite: The next step forward in global measurements of clouds, aerosols, precipitation, and radiation, B. Am. Meteorol. Soc., 96, 1311-1332, 2015.

Kneifel, S., Lerber, A., Tiira, J., Moisseev, D., Kollias, P., and Leinonen, J.: Observed relations between snowfall microphysics and triple-frequency radar measurements, J. Geophys. Res.Atmos., 120, 6034-6055, 2015.

Kollias, P. and Albrecht, B.: Why the melting layer radar reflectivity is not bright at $94 \mathrm{GHz}$, Geophys. Res. Lett., 32, L24818, https://doi.org/10.1029/2005GL024074, 2005.

Kollias, P., Albrecht, B., and Marks Jr, F.: Why Mie? Accurate observations of vertical air velocities and raindrops using a cloud radar, B. Am. Meteorol. Soc., 83, 1471-1484, 2002.

Kollias, P., Clothiaux, E., Miller, M., Albrecht, B. A., Stephens, G., and Ackerman, T.: Millimeter-wavelength radars: New frontier in atmospheric cloud and precipitation research, B. Am. Meteorol. Soc., 88, 1608-1624, 2007a.

Kollias, P., Miller, M. A., Luke, E. P., Johnson, K. L., Clothiaux, E. E., Moran, K. P., Widener, K. B., and Albrecht, B. A.: The Atmospheric Radiation Measurement Program cloud profiling radars: Second-generation sampling strategies, processing, and cloud data products, J. Atmos. Ocean. Tech., 24, 1199-1214, 2007b.

Kollias, P., Jo, I., Borque, P., Tatarevic, A., Lamer, K., Bharadwaj, N., Widener, K., Johnson, K., and Clothiaux, E. E.: Scanning ARM cloud radars, Part II: Data quality control and processing, J. Atmos. Ocean. Tech., 31, 583-598, 2014.

Kollias, P., McLaughlin, D., Frasier, S., Oue, M., Luke, E., and Sneddon, A.: Advances and applications in low-power phased array X-band weather radars, in: 2018 IEEE Radar Conference (RadarConf18), 23-27 April 2018, Oklahoma City, OK, USA, 1359-1364, https://doi.org/10.1109/RADAR.2018.8378762, 2018.

Kollias, P., Puigdomènech Treserras, B., and Protat, A.: Calibration of the 2007-2017 record of Atmospheric Radiation Measurements cloud radar observations using CloudSat, Atmos. Meas. Tech., 12, 4949-4964, https://doi.org/10.5194/amt-124949-2019, 2019.

Kollias, P., Bharadwaj, N., Clothiaux, E., Lamer, K., Oue, M., Hardin, J., Isom, B., Lindenmaier, I., Matthews, A., and Luke, E.: The ARM Radar Network: At the Leading Edge of Cloud and Precipitation Observations, B. Am. Meteorol. Soc., 101, 588607, 2020a.

Kollias, P., Luke, E., Oue, M., and Lamer, K.: Agile adaptive radar sampling of fast-evolving atmospheric phenomena guided by satellite imagery and surface cameras, Geophys. Res. Lett., 47, e2020GL088440, https://doi.org/10.1029/2020GL088440, $2020 b$.

Kumjian, M. R., Mishra, S., Giangrande, S. E., Toto, T., Ryzhkov, A. V., and Bansemer, A.: Polarimetric radar and aircraft obser- vations of saggy bright bands during MC3E, J. Geophys. Res.Atmos., 121, 3584-3607, 2016.

Lebsock, M. D., Suzuki, K., Millán, L. F., and Kalmus, P. M.: The feasibility of water vapor sounding of the cloudy boundary layer using a differential absorption radar technique, Atmos. Meas. Tech., 8, 3631-3645, https://doi.org/10.5194/amt-8-3631-2015, 2015.

Leinonen, J. and Szyrmer, W.: Radar signatures of snowflake riming: A modeling study, Earth Space Sci., 2, 346-358, 2015.

Lhermitte, R.: Attenuation and scattering of millimeter wavelength radiation by clouds and precipitation, J. Atmos. Ocean. Tech., 7, 464-479, 1990.

Lhermitte, R. M.: Cloud and precipitation remote sensing at 94 GHz, IEEE T. Geosci. Remote, 26, 207-216, 1988.

Li, H. and Moisseev, D.: Two layers of melting ice particles within a single radar bright band: Interpretation and implications, Geophys. Res. Lett., 47, e2020GL087499, https://doi.org/10.1029/2020GL087499, 2020.

Li, H., Tiira, J., von Lerber, A., and Moisseev, D.: Towards the connection between snow microphysics and melting layer: insights from multifrequency and dual-polarization radar observations during BAECC, Atmos. Chem. Phys., 20, 9547-9562, https://doi.org/10.5194/acp-20-9547-2020, 2020.

Liebe, H. J.: An updated model for millimeter wave propagation in moist air, Radio Sci., 20, 1069-1089, 1985.

Liebe, H. J., Hufford, G., and Cotton, M.: Propagation modeling of moist air and suspended water/ice particles at frequencies below $1000 \mathrm{GHz}$, in: Proc. A GARD Meeting Atmos. Propag. Effects Through Natural Man-Made Obscurants for Visible MMWave Radiation, 17-21 May 1993, Palma de Mallorca, Spain, 3/1-3/11, 1993.

Locatelli, J. D. and Hobbs, P. V.: Fall speeds and masses of solid precipitation particles, J. Geophys. Res., 79, 2185-2197, https://doi.org/10.1029/JC079i015p02185, 1974.

Matrosov, S. Y.: Attenuation-based estimates of rainfall rates aloft with vertically pointing Ka-band radars, J. Atmos. Ocean. Tech., 22, 43-54, 2005.

McIntosh, R. E., Narayanan, R. M., Mead, J. B., and Schaubert, D. H.: Design and performance of a $215 \mathrm{GHz}$ pulsed radar system, IEEE T. Microw. Theory, 36, 994-1001, 1988.

Mead, J. B., Mcintosh, R. E., Vandemark, D., and Swift, C. T.: Remote sensing of clouds and fog with a $1.4 \mathrm{~mm}$ radar, J. Atmos. Ocean. Tech., 6, 1090-1097, 1989.

Mead, J. B., PopStefanija, I., Kollias, P., Albrecht, B., and Bluth, R.: Compact airborne solid-state $95 \mathrm{GHz}$ FMCW radar system, in: 31st Int. Conf. on Radar Meteorology, 5-12 August 2003, Seattle, WA, USA, Abstract 4A.3, 2003.

Mishchenko, M. I., Travis, L. D., and Mackowski, D. W.: T-matrix computations of light scattering by nonspherical particles: a review, J. Quant. Spectrosc. Ra., 55, 535-575, 1996.

Nemarich, J., Wellman, R. J., and Lacombe, J.: Backscatter and attenuation by falling snow and rain at 96,140 , and $225 \mathrm{GHz}$, IEEE T. Geosci. Remote, 26, 319-329, 1988.

Oue, M. and Lamer, K.: Stony Brook Radar Observatory radar and lidar data for 25 February 2020, Stony Brook University, Academic Commons, available at: https://commons.library. stonybrook.edu/somasdata/12/, last access: 4 May 2021.

Pappalardo, G.: ACTRIS Aerosol, Clouds and Trace Gases Research Infrastructure, in: EPJ 
Web of Conferences, EDP Sciences, 176, 09004, https://doi.org/10.1051/epjconf/201817609004, 2018.

Roy, R., Lebsock, M., and Kurowski, M.: Spaceborne differential absorption radar water vapor retrieval capabilities in tropical and subtropical boundary layer cloud regimes, Atmos. Meas. Tech. Discuss. [preprint], https://doi.org/10.5194/amt-2021-111, in review, 2021.

Roy, R. J., Lebsock, M., Millán, L., Dengler, R., Rodriguez Monje, R., Siles, J. V., and Cooper, K. B.: Boundary-layer water vapor profiling using differential absorption radar, Atmos. Meas. Tech., 11, 6511-6523, https://doi.org/10.5194/amt11-6511-2018, 2018.

Roy, R. J., Lebsock, M., Millán, L., and Cooper, K. B.: Validation of a G-band differential absorption cloud radar for humidity remote sensing, J. Atmos. Ocean. Tech., 37, 1085-1102, 2020.

Sassen, K., Campbell, J. R., Zhu, J., Kollias, P., Shupe, M., and Williams, C.: Lidar and triple-wavelength Doppler radar measurements of the melting layer: A revised model for dark-and brightband phenomena, J. Appl. Meteorol., 44, 301-312, 2005.

Sassen, K., Matrosov, S., and Campbell, J.: CloudSat spaceborne $94 \mathrm{GHz}$ radar bright bands in the melting layer: An attenuationdriven upside-down lidar analog, Geophys. Res. Lett., 34, L16818, https://doi.org/10.1029/2007GL030291, 2007.

Stephens, G. L., Vane, D. G., Boain, R. J., Mace, G. G., Sassen, K., Wang, Z., Illingworth, A. J., O’Connor, E. J., Rossow, W. B., and Durden, S. L.: The CloudSat mission and the A-Train: A new dimension of space-based observations of clouds and precipitation, B. Am. Meteorol. Soc., 83, 1771-1790, 2002.

Stokes, G. M. and Schwartz, S. E.: The Atmospheric Radiation Measurement (ARM) Program: Programmatic background and design of the cloud and radiation test bed, B. Am. Meteorol. Soc., 75, 1201-1222, 1994.
Tokay, A., Wolff, D. B., and Petersen, W. A.: Evaluation of the new version of the laser-optical disdrometer, OTT Parsivel2, J. Atmos. Ocean. Tech., 31, 1276-1288, 2014.

Tridon, F., Battaglia, A., and Kollias, P.: Disentangling Mie and attenuation effects in rain using a Ka-W dual-wavelength Doppler spectral ratio technique, Geophys. Res. Lett., 40, 5548-5552, 2013.

Tridon, F., Battaglia, A., Chase, R. J., Turk, F. J., Leinonen, J., Kneifel, S., Mroz, K., Finlon, J., Bansemer, A., and Tanelli, S.: The Microphysics of Stratiform Precipitation During OLYMPEX: Compatibility Between Triple-Frequency Radar and Airborne In Situ Observations, J. Geophys. Res.-Atmos., 124, 8764 8792, 2019.

Tridon, F., Battaglia, A., and Kneifel, S.: Estimating total attenuation using Rayleigh targets at cloud top: applications in multilayer and mixed-phase clouds observed by ground-based multifrequency radars, Atmos. Meas. Tech., 13, 5065-5085, https://doi.org/10.5194/amt-13-5065-2020, 2020.

Westbrook, C. D., Ball, R., Field, P., and Heymsfield, A. J.: Universality in snowflake aggregation, Geophys. Res. Lett., 31, L15104, https://doi.org/10.1029/2004GL020363, 2004.

Wolfensberger, D., Scipion, D., and Berne, A.: Detection and characterization of the melting layer based on polarimetric radar scans, Q. J. Roy. Meteor. Soc., 142, 108-124, 2016.

Zhu, Z., Lamer, K., Kollias, P., and Clothiaux, E. E.: The Vertical Structure of Liquid Water Content in Shallow Clouds as Retrieved from Dual-wavelength Radar Observations, J. Geophys. Res.-Atmos., 124, 14184-14197, 2019. 